OPEN ACCESS

Edited by:

Tarun Goswami,

Wright State University, United States

Reviewed by: Lindsey Westover,

University of Alberta, Canada

Francesco Travascio

University of Miami, United States

${ }^{*}$ Correspondence:

Chris A. McGibbon

cmcgibb@unb.ca

Specialty section This article was submitted to Biomechanics,

a section of the journal Frontiers in Bioengineering and Biotechnology

Received: 10 September 2020 Accepted: 15 December 2020 Published: 28 January 2021

Citation: McGibbon CA, Brandon S, Bishop EL, Cowper-Smith C and Biden EN (2021) Biomechanical Study of a Tricompartmental Unloader Brace for Patellofemoral or Multicompartment Knee Osteoarthritis.

Front. Bioeng. Biotechnol. 8:604860. doi: 10.3389/fbioe.2020.604860

\section{Biomechanical Study of a Tricompartmental Unloader Brace for Patellofemoral or Multicompartment Knee Osteoarthritis}

\author{
Chris A. McGibbon ${ }^{1 *}$, Scott Brandon ${ }^{2}$, Emily L. Bishop ${ }^{3}$, Chris Cowper-Smith ${ }^{4}$ and \\ Edmund N. Biden ${ }^{5}$ \\ ${ }^{1}$ Faculty of Kinesiology and Institute of Biomedical Engineering, University of New Brunswick, Fredericton, NB, Canada, \\ ${ }^{2}$ School of Engineering, University of Guelph, Guelph, ON, Canada, ${ }^{3}$ Department of Mechanical and Manufacturing \\ Engineering, University of Calgary, Calgary, AB, Canada, ${ }^{4}$ Spring Loaded Technologies, Halifax, NS, Canada, ${ }^{5}$ Department of \\ Mechanical Engineering and Institute of Biomedical Engineering, University of New Brunswick, Fredericton, NB, Canada
}

Objective: Off-loader knee braces have traditionally focused on redistributing loads away from either the medial or lateral tibiofemoral (TF) compartments. In this article, we study the potential of a novel "tricompartment unloader" (TCU) knee brace intended to simultaneously unload both the patellofemoral (PF) and TF joints during knee flexion. Three different models of the TCU brace are evaluated for their potential to unload the knee joint.

Methods: A sagittal plane model of the knee was used to compute PF and TF contact forces, patellar and quadriceps tendon forces, and forces in the anterior and posterior cruciate ligaments during a deep knee bend (DKB) test using motion analysis data from eight participants. Forces were computed for the observed (no brace) and simulated braced conditions. A sensitivity and validity analysis was conducted to determine the valid output range for the model, and Statistical Parameter Mapping was used to quantify the effectual region of the different TCU brace models.

Results: PF and TF joint force calculations were valid between $\sim 0$ and 100 degrees of flexion. All three simulated brace models significantly $(p<0.001)$ reduced predicted knee joint loads (by 30-50\%) across all structures, at knee flexion angles $>\sim 30$ degrees during DKB.

Conclusions: The TCU brace is predicted to reduce PF and TF knee joint contact loads during weight-bearing activity requiring knee flexion angles between 30 and 100 degrees; this effect may be clinically beneficial for pain reduction or rehabilitation from common knee injuries or joint disorders. Future work is needed to assess the range of possible clinical and prophylactic benefits of the TCU brace.

Keywords: knee brace, patellofemoral force, tibiofemoral force, simulation, osteoarthritis, tendon force, cruciate force, deep knee bend 


\section{INTRODUCTION}

Knee braces are a common conservative treatment option for reducing pain and improving function in people with musculoskeletal injuries and disease (Chew et al., 2007), such as knee osteoarthritis (OA) (Ramsey and Russell, 2009; Petersen et al., 2016; Phillips et al., 2016). Unicompartment off-loader braces are a common style of knee brace designed to reduce pain and progressive degeneration of the osteoarthritic knee by redistributing compressive forces away from the diseased medial or lateral tibiofemoral (TF) compartment via joint realignment (Ramsey et al., 2007; Briem and Ramsey, 2013). Although the use of these braces in patients with unicompartmental TF disease is supported by biomechanical (Moyer et al., 2015; Petersen et al., 2016) and clinical studies (Rannou et al., 2010; Mistry et al., 2018), the effectiveness of unicompartment off-loader braces may be limited because the vast majority $(>90 \%)$ of patients have bicompartmental or tricompartmental disease with patellofemoral (PF) involvement (Duncan et al., 2009; Heekin and Fokin, 2014).

A new brace concept was recently introduced to provide simultaneous unloading (rather than off-loading) benefits to multiple knee compartments (i.e., TF and PF compartments) by reducing sagittal plane muscle effort (Budarick et al., 2020), with the goal of reducing pain and improving joint function for individuals with multicompartmental knee OA (Waller et al., 2011). The Levitation ${ }^{\circledR}$ Tri-Compartment Unloader (Spring Loaded Technology Inc., Halifax, Nova Scotia, Canada), herein referred to as the tricompartment unloader (TCU) (Figure 1), is a passive mechanical brace capable of energy storage and body weight (BW) support during gravity assisted knee flexion (such as lowering to a squat). Stored energy is then returned to the user during antigravity motion (such as rising from a squat). There are currently three TCU brace models available from the manufacturer, which provide different levels of assistance across the range of motion of the brace. These brace models are designed for different therapeutic purposes or to meet varying user requirements. As muscles are the primary contributors to $\mathrm{PF}$ and TF joint contact loads that increase during weightbearing flexion (Kuster, 2002; Winby et al., 2009; Sasaki and Neptune, 2010; Trepczynski et al., 2012), reduction in muscle effort should reduce the forces transmitted through the joint structures (Budarick et al., 2020). As in vivo measurements are generally infeasible, a model is required to quantify these effects.

There are a wide variety of models in literature that can be used to estimate changes in knee loads due to an assistive brace [see review in Fregly et al. (2012)]. On one end of the spectrum, finite element models provide high-resolution estimates of tissuelevel stress and strain but at high computational cost (Kazemi et al., 2013; Shriram et al., 2019). Conversely, reductionist models (Morrison, 1968; Wismans et al., 1980; Yamaguchi and Zajac, 1989) rely on simplifying assumptions to lump or omit some tissues, but may still be of sufficient quality to reveal the net action of load-bearing structures of the knee (Dumas et al., 2019) and to estimate the unloading effect of a knee brace (Pollo et al., 2002; Budarick et al., 2020). Regardless of the modeling approach, validation is both crucial and challenging (Hicks et al., 2015).
Because the TCU brace acts primarily in the sagittal plane, in the present study we chose a planar model of the knee previously described by O'Connor et al. (1989) and expanded upon in several studies (Collins and O'Connor, 1991; Zavatsky and O'Connor, 1992a,b; Lu and O'Connor, 1996; Wilson et al., 1998; Huss et al., 2000; Imran et al., 2000). The model is based on the crossed four-bar geometry of the anterior and posterior cruciate ligaments (ACL and PCL, respectively), which governs TF and PF contact kinematics. When coupled with external loads from foot-floor reactions, limb inertia and gravity, and forces applied from an external source (such as a brace or other orthotic), this model can readily compute forces in the extensor (quadriceps) or flexor (hamstrings) tendons, the ACL or PCL, and TF and PF contact forces.

The main objective of this study was to use the model, with kinematic and kinetic motion analysis data from healthy participants, to simulate the biomechanical effects of wearing the different TCU brace models during a weight-bearing deep knee flexion activity. The deep knee bend (DKB) test is commonly used in clinical studies of the knee (Stiehl et al., 2001; Komistek et al., 2003; Argenson et al., 2004) as it is known to increase knee joint force (Kutzner et al., 2013) and often results in increased pain and/or dysfunction in patients with knee OA (Wijayaratne et al., 2007).

Because the intended function of the TCU brace is to reduce TF and PF contact forces during weight-bearing knee flexion, it is important to be confident in the predictions of the model. The secondary objective was therefore to establish the fidelity of the model predictions. To this end, we evaluated the sensitivity of the force predictions to uncertainties in knee model geometry and validated the model output against a criterion standard, in this case the Grand Challenge (GC) data from Fregly et al. (Fregly et al., 2012), as well as other published literature. This allowed us to define a valid range within which to compare the simulated braced condition for the different TCU brace models with the non-braced condition, and make conclusions about TCU unloading behavior.

\section{MATERIALS AND METHODS}

\section{Motion Analysis Dataset}

Three-dimensional (3D) human movement data for healthy participants who participated in a different study (Mohamed et al., 2019) were used in this simulation study. Data from fourteen participants who performed a DKB test were screened for inclusion in this study, requiring that peak knee flexion angle during the DKB task was $\leq 135$ degrees, due to constraints of the knee model (O'Connor et al., 1989). This resulted in a sample of eight participants (age $25 \pm 5$ years, mass $66 \pm 12 \mathrm{~kg}$, height $164 \pm 8 \mathrm{~cm}$, six females). The DKB test protocol is detailed elsewhere (Mohamed et al., 2012). Briefly, participants stood with each foot on side-by-side force plates and completed the DKB task three times. All participants provided informed consent for the original study, and the present secondary analysis of their data was approved by the university research ethics board. 


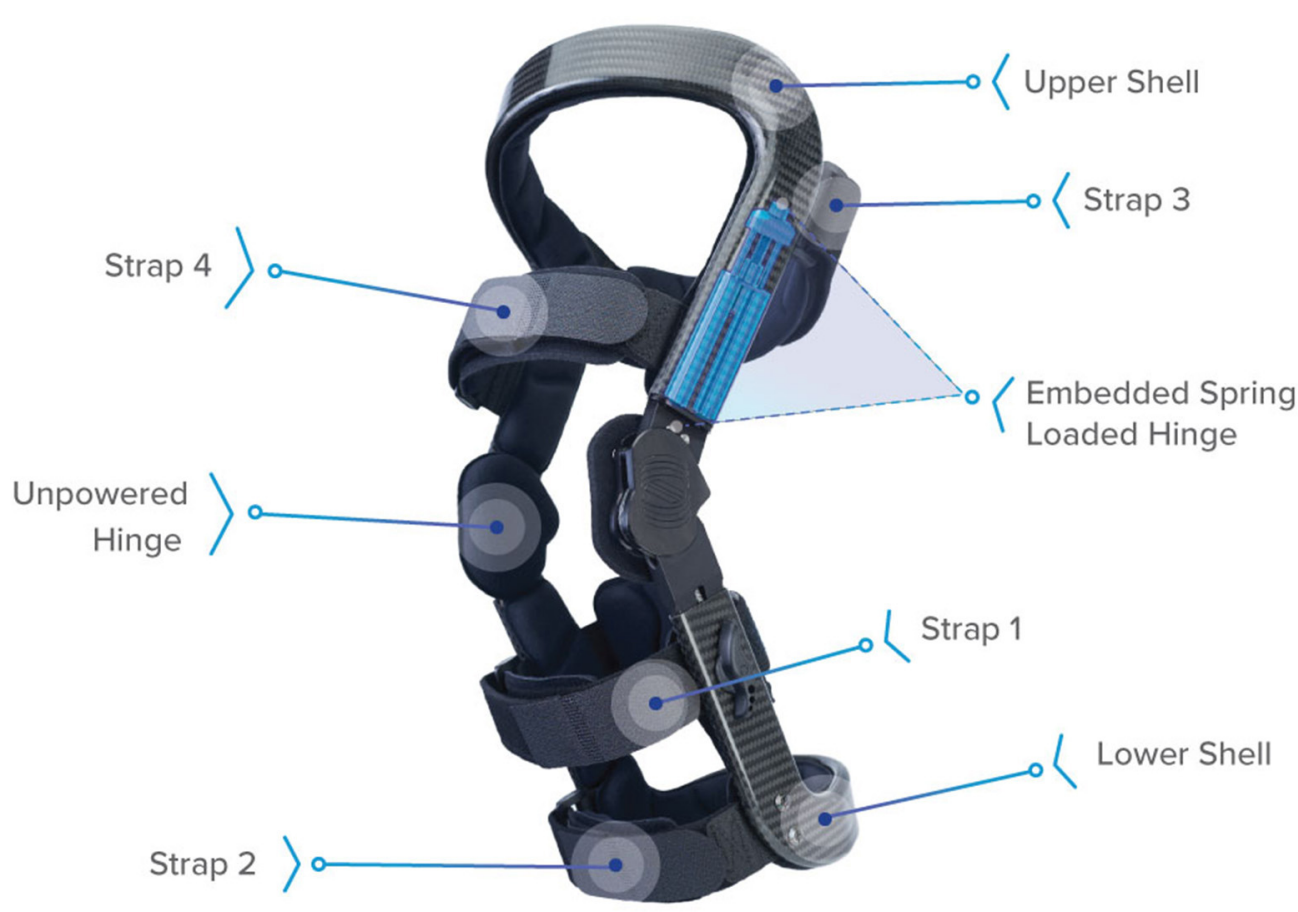

FIGURE 1 | Levitation $^{\text {TM }}$ tricompartment unloader brace (Spring Loaded Technologies, Halifax, Nova Scotia, Canada). Components include straps to attach the brace to the leg, upper and lower carbon-fiber shells, and spring-powered and unpowered hinges. When the knee joint is flexed (e.g., during a squat), the spring-powered lateral hinge applies an assistive extension moment to reduce the user's quadriceps muscle effort. This assistive moment is transferred to the back of the user's leg via reaction forces at the proximal strap (Strap 3) and lower shell and cuff as an anteriorly directed force, 20 cm above- and below-knee center (Budarick et al., 2020).

\section{Biomechanical Knee Model Lower Leg and Knee Model}

A 3D inverse dynamics model of the lower-leg and foot (McGibbon et al., 2017) was used to compute net forces at the knee joint. Then, a sagittal plane model of the knee (O'Connor et al., 1989), as shown in Figure 2, was used to resolve muscle tendon forces, cruciate ligament forces, and joint contact forces in the sagittal plane. Model geometry (see Supplementary Material Appendix I, Table A1) was scaled to each participant's tibia length.

The knee kinematic model, first described by Kapandji (1987) and later expanded by O'Connor and colleagues (O'Connor et al., 1989; Collins and O'Connor, 1991; Zavatsky and O'Connor, 1992a,b; Lu and O'Connor, 1996; Wilson et al., 1998; Huss et al., 2000; Imran et al., 2000), treats the cruciate ligaments as having a theoretical isometric fiber that, in combination with the TF contact surfaces, can be modeled as a crossed four-bar linkage where the moving (femoral) condyle rolls and slides on the fixed (tibia) plateau as a function of knee flexion angle. The knee flexor and extensor mechanisms were modeled as described by O'Connor et al. (1990a,b). The kinematic model is described in detail in Supplementary Material Appendix I.

Given a prescribed knee flexion angle, the kinematic model outputs the origin and orientation of the ACL and PCL lines of action (LoA), TF contact LoA, hamstring tendon LoA, and LoA of the quadriceps mechanisms (patellar tendon, quadriceps muscle tendon, and PF contact). As such, the force system at the proximal tibia (Figure 2) is underdetermined with six unknown forces to achieve dynamic equilibrium: hamstring tendon force $\left(F_{\mathrm{HT}}\right)$, patellar tendon force $\left(F_{\mathrm{PT}}\right)$, anterior cruciate force $\left(F_{\mathrm{AC}}\right)$, posterior cruciate force $\left(F_{\mathrm{PC}}\right)$, and $\mathrm{TF}$ contact force $\left(F_{\mathrm{TF}}\right)$. At each instant in time, the system was reduced into four fully determined candidate solutions, each consisting of the only three forces $\left(F_{\mathrm{TF}}\right.$, plus one cruciate and one tendon force). The candidate solution yielding a tensile (positive) ligament and tendon force, and lowest compressive (negative) contact force, was retained (see Supplementary Material Appendix for details). If the patellar tendon force was non-zero, $\mathrm{PF}$ contact force $\left(\mathrm{F}_{\mathrm{PF}}\right)$ and quadriceps tendon force $\left(F_{\mathrm{QT}}\right)$ were determined by treating the patella as a 3 -force body.

\section{Sensitivity and Validity}

Because this was a retrospective simulation where participants' data did not include detailed quantification of subject-specific knee geometry (e.g., medical imaging), it was important to first evaluate the sensitivity of the model to uncertainty in knee geometry input parameters. Therefore, a parameter analysis was conducted using estimated uncertainties of each input parameters of the knee geometry model. Uncertainties were assumed to be $\delta v+/-5 \mathrm{~mm}$ in linear dimensions and $\delta v+/-$ 5 degrees in angular dimensions (see Table A.1 for details). These values were based on measurement precision of joint tissue attachments from magnetic resonance imaging (MRI) studies (Bosmans et al., 2015).

In this analysis, inertial contributions (mass, mass moment of inertia, and limb accelerations) and ground reaction forces 


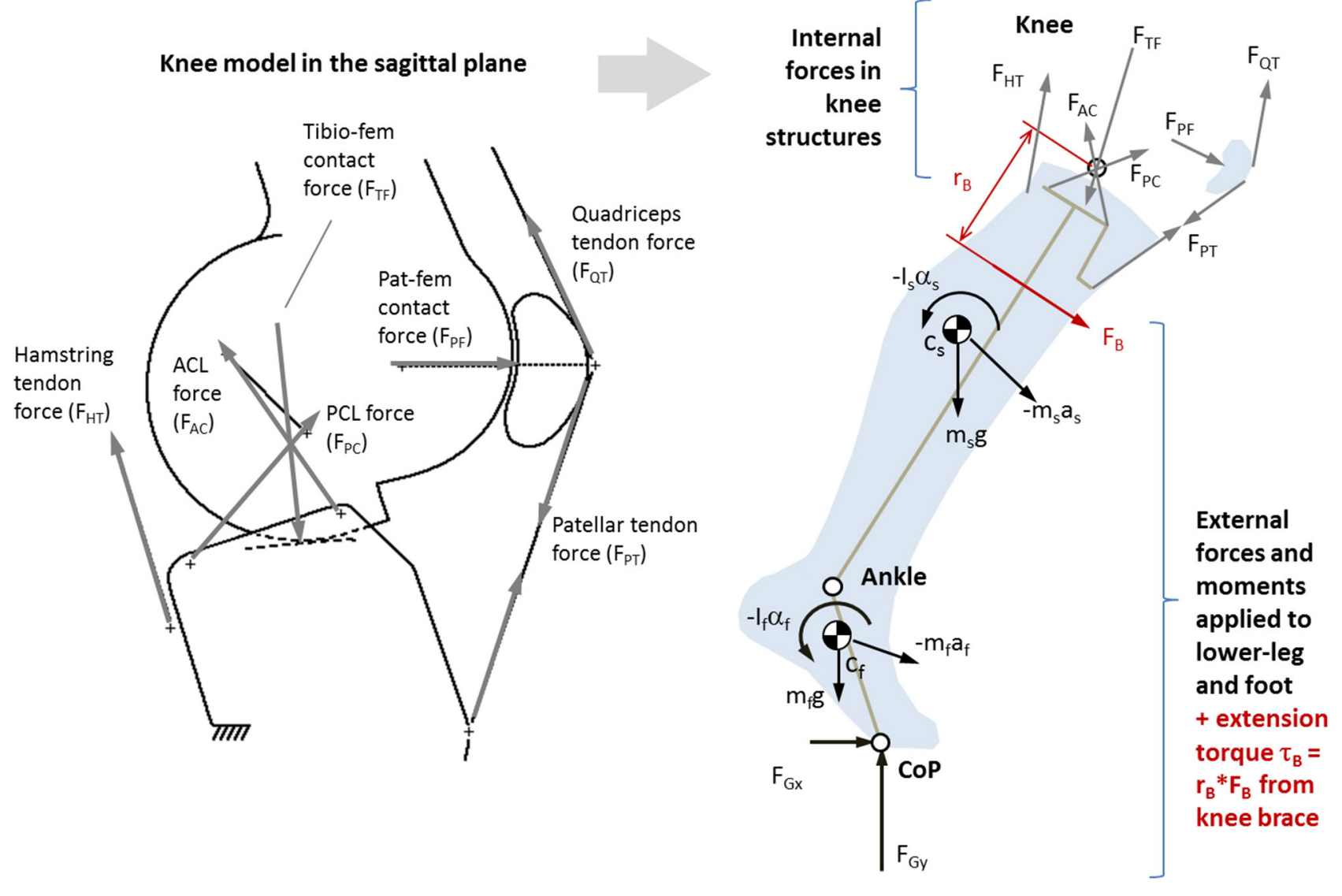

FIGURE 2 | Left: Single degrees-of-freedom kinematic knee model used to determine position and orientation of major load-bearing knee structures ( $\bigcirc$ 'Connor et al., 1990a). Right: Sagittal plane (2D) biomechanical model of the lower-leg and knee based on O'Connor et al. (1990b), where ground forces and segmental kinematics come from 3D gait analysis. Also shown is a moment of force caused by an external source (such as an active brace) $F_{\mathrm{B}}$ acting with moment arm $r_{\mathrm{B}}$.

were assumed true. An expanded Taylor's series was used to combine the parametric output uncertainties $\left(\delta F_{v i}\right)$, based on the maximum likelihood estimator:

$$
\delta F=\sqrt{\frac{\left(\sum_{v i=1}^{M} \delta F_{v i}^{2}\right)}{M}}
$$

where $M$ is the number of variables included in the sensitivity analysis, where $M=14$ in this study.

In order to determine which parameter uncertainties were most influential, each parameter's contribution $\left(\varepsilon_{v \mathrm{i}}\right)$ to the total uncertainty was expressed by rearranging the above equation and normalizing the left side to unity by dividing parameter squared uncertainties by total squared uncertainty.

$$
\begin{aligned}
1= & \left(\delta F_{v 1}^{2}+\delta F_{v 2}^{2}+\cdots+\delta F_{v M}^{2}\right) /\left(\delta F^{2} M\right)=\varepsilon_{v 1}+\varepsilon_{v 2}+\cdots \\
& +\varepsilon_{v M}
\end{aligned}
$$

or

$$
\begin{aligned}
\varepsilon_{v} 1 & =\delta F_{v 1}^{2} /\left(\delta F^{2} M\right) ; \varepsilon_{v} 2=\delta F_{v 2}^{2} /\left(\delta F^{2} M\right) ; \cdots ; \varepsilon_{v M} \\
& =\delta F_{v M}^{2} /\left(\delta F^{2} M\right)
\end{aligned}
$$

In order to evaluate the overall sensitivity of the force outputs to input geometry uncertainties, the "variability ratio" of mean sum of square errors $\delta F^{2}$ to between-subject variability $\sigma_{F}{ }^{2}$ (variance of force across participants) was computed.

$$
v=\frac{\delta F^{2}}{\sigma_{F}^{2}}
$$

A variability ratio $v<<1$ would indicate that parameter sensitivity is less a concern than natural between-subject variability, whereas $v$ approaching or greater than unity would suggest model results may not be trusted. We arbitrarily selected a ratio of $20 \%(v=0.2)$ as the threshold of acceptability.

Finally, to determine the range in which the knee model is valid, a two-legged DKB activity was simulated using published motion capture data from $N=4$ participants with instrumented TKR from the $3 \mathrm{rd}$ (male, mass $=70 \mathrm{~kg}$, height $=172 \mathrm{~cm}$ ), 4th (male, $75 \mathrm{~kg}, 180 \mathrm{~cm}$ ), 5th (male, $66.7 \mathrm{~kg}, 168 \mathrm{~cm}$ ), and 6th (female, $78.4 \mathrm{~kg}, 167 \mathrm{~cm}$ ) GC competitions to predict in vivo knee forces (Fregly et al., 2012). Model predictions of TF forces were compared with synchronized in vivo measurements using root mean square error (RMSE) and reported as a function of knee 


\section{Deep knee bend with simulated knee assist brace}

A

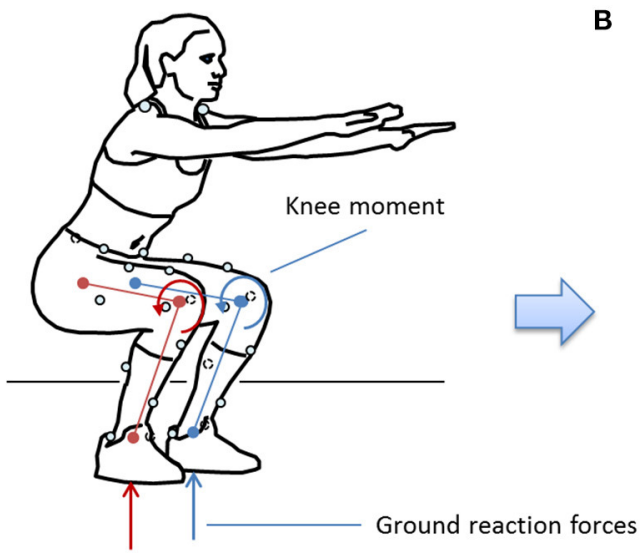

B

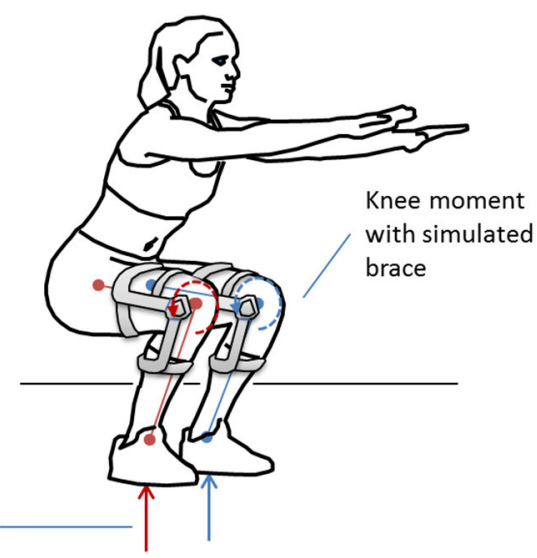

FIGURE 3 | Deep knee bend test: (A) observed test without brace, (B) simulated test with brace.

angle. These data were used to specify the knee flexion range where the model sufficiently agrees (95\% confidence interval) with in vivo measured forces.

\section{TCU Brace Simulation}

\section{Simulation}

The simulation was predicated on the assumption that participants could, in theory, produce the same kinematics and ground reaction forces as the non-braced condition for each of the simulated brace conditions (Brandon et al., 2019), as illustrated in Figure 3. In this way, the simulation can be used to study the response of knee tissue forces for different TCU brace models relative to the no-brace condition to provide a scientific justification for advancing to human trials of the brace.

The design of the TCU brace is detailed elsewhere (Budarick et al., 2020). Briefly, the brace is coupled to the upper and lower leg in a similar manner to traditional rigid frame knee braces. Unlike traditional knee braces, the lateral hinge contains a powerful liquid spring to absorb BW and assist the extensor mechanism in the sagittal plane by applying an external torque to the knee, via a force couple created by the cuff contact points on the leg. For the purpose of a ground-up analytical approach, the brace extension assist moment is transferred to the back of the lower leg $\sim 20 \mathrm{~cm}$ below the knee center. Brace moment arm $r_{\mathrm{B}}$ was therefore assumed to be fixed at $20 \mathrm{~cm}$.

Three different TCU brace models (squat, plateau, and general) were considered in this study (Table 1). The corresponding brace moment/angle calibration curves were determined by the manufacturer using bench experiments, as described in (Budarick et al., 2020) (Figure 4). For this proofof-concept study, the brace was modeled as a force $F_{\mathrm{B}}$ applied perpendicular to the tibia located distance $r_{\mathrm{B}}$ below the knee. $F_{\mathrm{B}}$ magnitude was calculated from the moment/knee flexion curve using a look-up table where the input was knee angle, and output was brace force (moment divided by $0.02 \mathrm{~m}$ ) in Newtons (N).
TABLE 1 | Simulated brace conditions.

\begin{tabular}{ll}
\hline Brace condition & Description \\
\hline No brace & $\begin{array}{l}\text { Brace moment is 0 at all knee angles (observed } \\
\text { case). } \\
\text { Brace model 1-squat }\end{array}$ \\
$\begin{array}{l}\text { Brace moment increases with knee angle in an } \\
\text { approximate linear fashion. This brace model } \\
\text { should provide the greatest amount of knee } \\
\text { assist throughout the range of knee motion of a } \\
\text { squat. } \\
\text { Brace model 2-general }\end{array}$ & $\begin{array}{l}\text { gradually at first and with increasing force at } \\
\text { higher flexion angles. This brace model was } \\
\text { designed for general purpose use. } \\
\text { Brace moment increases with knee angle but } \\
\text { plateaus at } ~ 100-110 \text { degrees of knee flexion. } \\
\text { This brace model supports the knee at lower } \\
\text { flexion angles. }\end{array}$ \\
\hline
\end{tabular}

\section{Statistical Analysis}

We compared non-brace and brace conditions using Statistical Parameter Mapping (SPM), a relatively recent waveform analysis technique. Detailed description of this analysis technique can be found elsewhere (Kiebel and Friston, 2004; Pataky et al., 2014, 2016). Briefly, SPM operates analogous to standard $t$-test and analysis-of-variance tests but considers the whole (or part of the) waveform for comparison, identifying the region where the waveforms significantly (at a selected $\alpha$ level) depart from one another. We denote this region as the "effectual region" of the brace assist. The effectual region was thus defined by the region where the continuum of $t$ scores across the waveform comparison exceeded the critical $t$ score $\left(t^{*}\right)$ at the selected $\alpha$ level. We used the SPM analog of the paired $t$-test, with Bonferroni $\alpha$ correction to account for multiple comparisons of the three braced conditions to the non-braced condition $(\alpha=0.067)$. For ease of interpretation, we also compared peak forces at an 


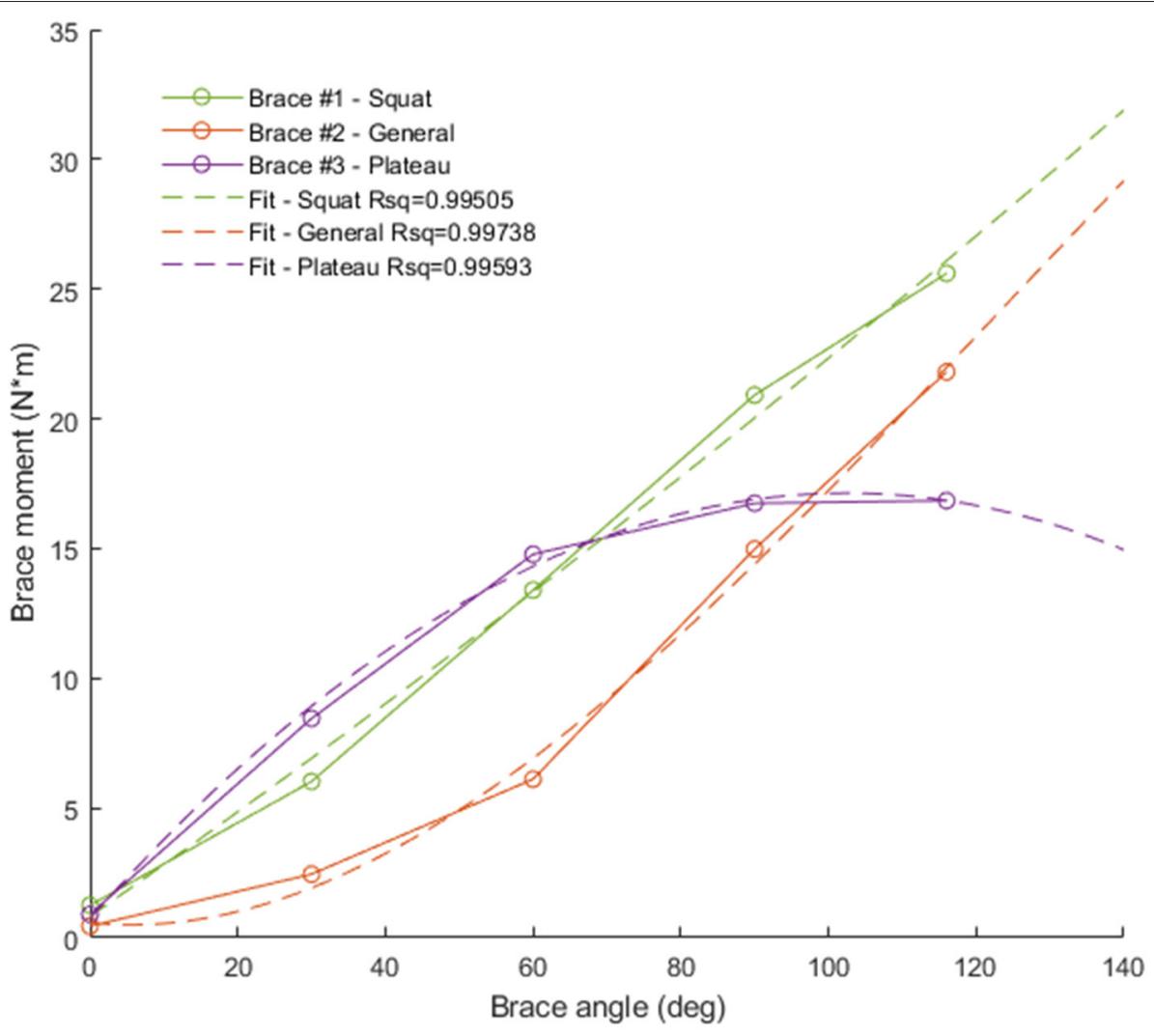

FIGURE 4 | Brace moment/angle curves used in the simulation. Green = squat brace (brace \#1, linear fit), red = general brace (brace \#2, quadratic fit), purple = plateau brace (brace \#3, quadratic fit).

arbitrary knee flexion angle of 90 degrees using paired $t$-tests $(\alpha=0.067)$, which represents a reasonably deep squat within the valid range of our model.

\section{RESULTS}

\section{Biomechanical Knee Model}

Mean knee forces during DKB are shown in Figure 5. Figures 5A,C show QT, PT, and PF forces, whereas Figures 5B,D show AC, PC, and TF forces. Extensor mechanism forces were highest for QT followed by PF and PT forces. For the cruciate-TF complex, forces were highest for the TF contact force, followed by the PC and AC ligaments. The AC ligament was only loaded in the early and late portions of the $\mathrm{DKB}$, with the PC ligament supporting the shear force across the knee during midportion of the DKB. As shown by the shaded boundaries, subject variability (Figures 5C,D) was higher than model uncertainty (Figures 5A,B), except toward the midportion of DKB.

Variability ratio $(v)$ using Equation (4) is plotted as a function of knee flexion angle (for the DKB descent phase) in Figure 6. For QT force, TF, and PF contact forces, the sensitivity of the model to geometric parameters is negligible in comparison with between-subject variability up until $\sim 60$ degrees of knee flexion, after which it starts to increase. The dashed horizontal projection lines at a variability threshold of $v=0.2$ are shown intersecting the curve at knee angles of 90 degrees or higher for QT, PF, and TF forces. The PC ligament force, however, remained (when active) above this threshold after 50 degrees and reached unity at $\sim 115$ degrees.

Evaluation of the model using data from four participants in the GC dataset is summarized in Figure 7. Model predictions of TF contact force followed the general pattern of in vivo measurements, increasing with knee flexion angle and reaching 23.5 BW at 100 degrees of knee flexion (Figure 7A). RMSE prediction error was $0.7 \mathrm{BW}$ between 0 and 100 degrees of knee flexion, but larger (1.1 BW) across the entire DKB motion. Predictions agreed with in vivo measurements (i.e., $95 \%$ confidence interval included 0 ) until $\sim 100$ degrees of knee flexion, with a bias toward overestimation (Figure 7B). The largest prediction error ( $>2 \mathrm{BW}$ ) was observed at high flexion angles (>110 degrees), which were achieved by only one of the four total knee arthroplasty (TKA) participants.

Both the sensitivity analysis and the validity analysis indicate that the region of knee flexion where joint forces from the analytical knee model may be considered trustworthy is $\sim 0$ to 100 degrees of knee flexion.

\section{TCU Brace Simulation}

SPM analysis results are summarized in Figure 8. Effectual regions $(\alpha=0.067)$ of the non-braced condition vs. each of the 


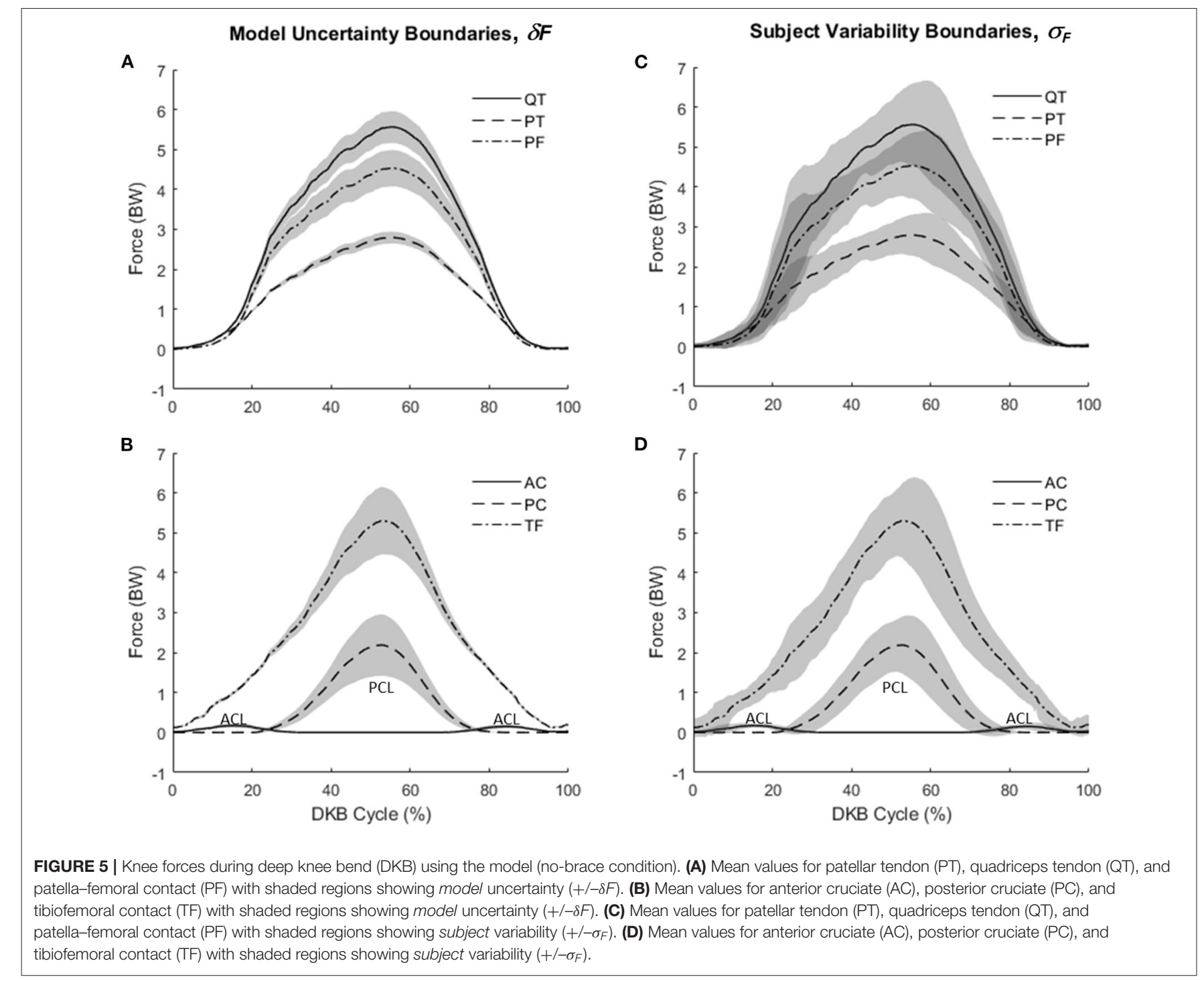

braced conditions (squat, general, and plateau) are shown by horizontal bars at the bottom of each plot. These are the regions where the braced condition resulted in significant reduction of knee tissue force relative to the non-braced condition. Vertical dashed lines show the $t^{*}$ threshold crossings and the corresponding knee flexion angle (shown in Figure 8, top left) at which they occur. Text inside the horizontal bars shows the critical $t^{*}$ values and corresponding $p$ values. The effectual range of the squat and plateau brace models occurred at knee angles $>15-20$ degrees for PT, QT, and TF forces; >40 degrees for PF force; and >95 degrees for PC ligament force. Effectual range for the general brace model was consistently smaller than for the squat and plateau brace models; for example, the general brace model required knee angles $>50$ degrees of flexion to reduce the PF contact force.

Mean knee forces at 90 degrees of flexion during descent and ascent portions of the DKB are summarized in Table 2 for the non-braced condition and each of the three simulated braced conditions.

Knee forces were significantly $(p<0.001)$ reduced for all three simulated brace models compared to the observed non-braced condition. Effect sizes were large $(d>4$, Table 2) for all joint structures except the AC ligament, which is not loaded throughout most of the DKB (Figure 5B). The squat brace provided the largest unloading effect across all structures ( $>43 \%$ reduction), followed by the plateau brace $(>37 \%$ reduction) and the general brace $(>32 \%$ reduction). For the squat brace, the PC ligament force was most reduced (68\% reduction), followed by $\mathrm{PT}, \mathrm{PF}$, and QT forces (46\% reduction) and $\mathrm{TF}$ contact (43\% reduction). Note, however, that the reduction of PC ligament forces reported should be interpreted with caution because of observed PC force sensitivity to modeling assumptions (Figure 6). 
Variability Ratio $\left(\delta \mathrm{F}^{2} / \sigma_{\mathrm{F}}^{2}\right)$ for Knee Model Outputs
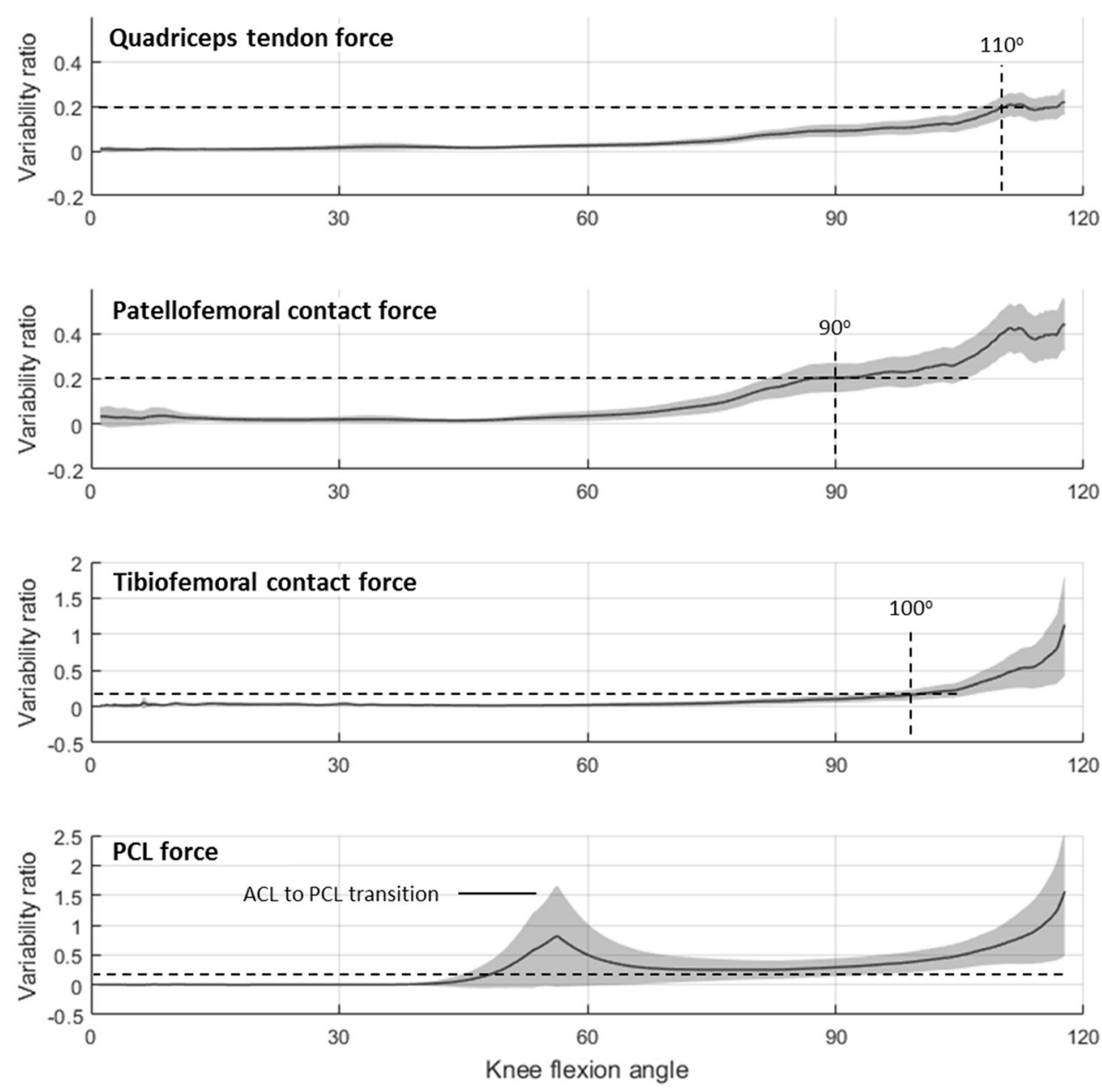

FIGURE 6 | Variability ratio (mean sum of square errors $\delta F^{2}$ divided by between-subject variance $\sigma_{F}{ }^{2}$ ) in knee force estimates over the range of knee flexion during the deep knee bend (DKB) task for quadriceps tendon, patella-femoral contact, tibiofemoral contact and PCL (no-brace condition).

\section{DISCUSSION}

Unloading of joint contact forces is widely recognized as a best practice in the conservative care of knee OA patients and may be achieved through a range of strategies including BW reduction, activity modification, strengthening/exercise, and the use of walking aids or knee braces (Sarzi-Puttini et al., 2005; Zhang et al., 2008; Waller et al., 2011; Messier et al., 2018; Mistry et al., 2018). Joint unloading can result in clinically significant improvements in pain, function, and quality of life (Waller et al., 2011; Messier et al., 2018; Mistry et al., 2018) and may be used as a strategy to delay or prevent surgery (Lee et al., 2017) or even slow the progression of knee OA (Radin and Burr, 1984; Block and Shakoor, 2009; Mastbergen et al., 2013; van der Woude et al., 2017). This study analyzed the biomechanics of the knee joint for three different models of a novel TCU brace, which is designed to reduce joint forces in all three knee compartments when the knee is flexed and weight-bearing.
Compared to the non-braced condition, significant force reduction was predicted for all major structures of the knee during the DKB task for the simulated TCU braced conditions. Because of its large assistive moment (Figure 4), the squat brace model provided the highest reduction in force, followed by the plateau brace and then the general brace. The squat and plateau braces were effectual (i.e., provided a significant reduction in force) beyond 20 degrees of knee flexion for TF and QT forces and beyond 50 degrees of knee flexion for PF forces. This result demonstrates multicompartment unloading beyond 50 degrees of knee flexion with the squat and plateau braces during the DKB. More specifically, QT, PT, PF, and TF forces were reduced by $>40 \%$ with the squat brace at 90 degrees of flexion compared to the non-braced condition. In comparison, the general brace was effectual at reducing PF and QT forces beyond 60 degrees of knee flexion, and TF forces were significantly reduced beyond 70 degrees of knee flexion. Therefore, the general brace may also provide multicompartment 

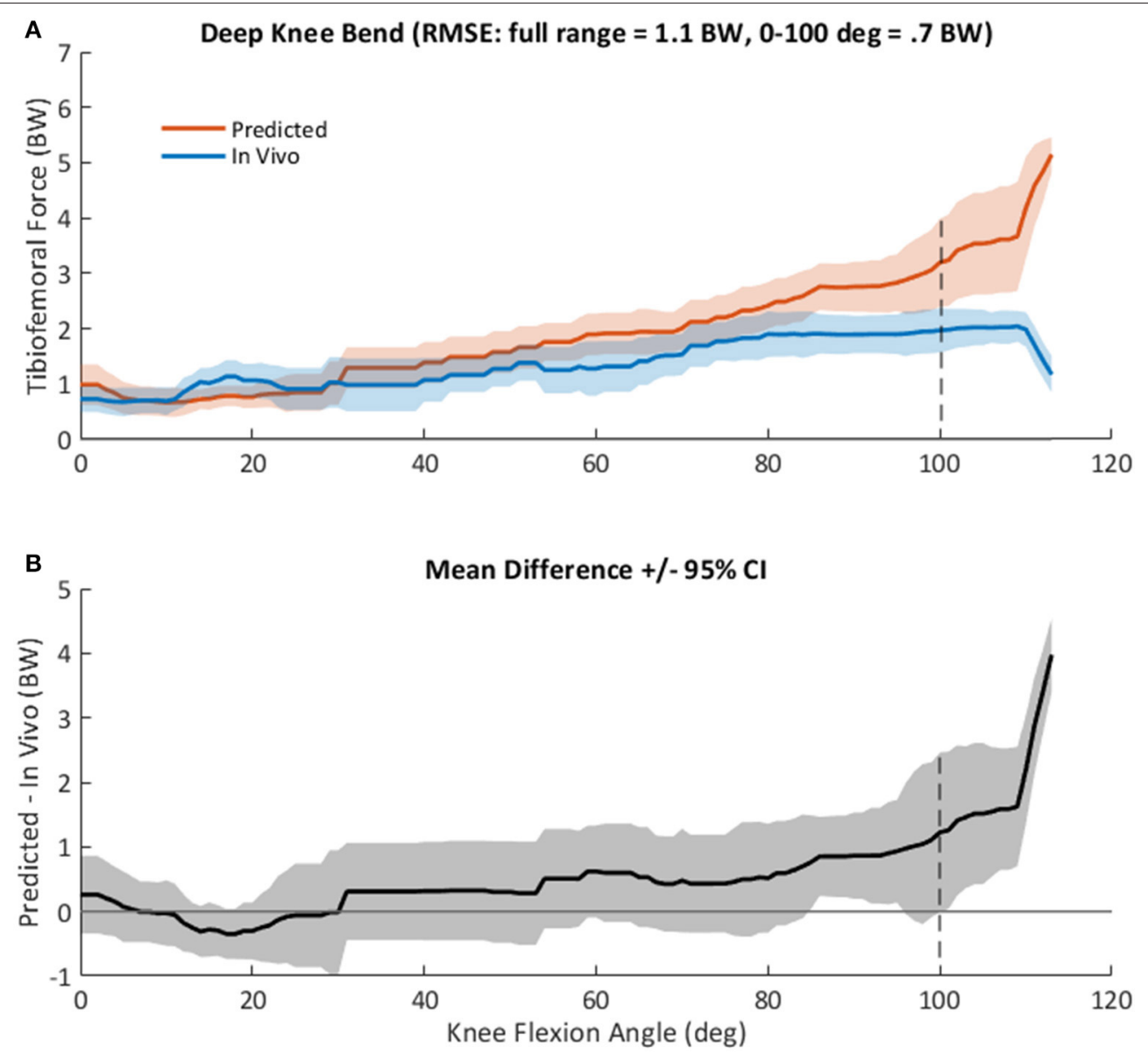

FIGURE 7 | (A), Mean $+/$ - standard deviation (SD) tibiofemoral contact force, $F_{\mathrm{TF}}$, as predicted by the computational knee model (red), and as measured in vivo from the instrumented tibial implant (blue) in four subjects during a squat activity (Winby et al., 2009). Root mean square prediction error was 1.1 times body weight (BW) across the entire range, but only 0.7 BW at knee angles $<100$ degrees. (B), Mean $+/-95 \%$ confidence interval of the difference between predicted and measured knee loads, as shown in (A) vs. knee flexion angle across all subjects.

unloading $(\sim 30 \%$ reduction); however, higher knee flexion angles are required to achieve this in comparison to the squat and plateau braces.

It was also apparent that the effectual region was not symmetric with respect to descent and ascent phases. As shown in Figure 8, the limit of the effectual region for each brace model occurred at a smaller knee flexion angle during descent than ascent. As the brace moment/angle curves were functions of flexion angle alone, without hysteresis, this differential performance between descent and ascent (see also Table 2) is attributed to biomechanical (or inertial) differences in each phase of the DKB test. Indeed, while the knee flexion angle was relatively symmetrical in time with a peak near $50 \%$ of the cycle, the joint tissue loads (QT, PT, PF; Figures 5, 8) exhibited skewed curves with much later peaks ( $\sim 60 \%$ cycle). It is likely this asymmetrical behavior would also be present in the real-life behavior of the brace and therefore should be taken into account when interpreting the data.

\section{Mechanism of Joint Unloading With the TCU}

The observed reduction in QT force with all three brace models suggests reduced sagittal plane muscle effort with TCU brace use. This provides evidence in support of the proposed mechanism of unloading, whereby reduced quadriceps muscle effort is expected to correspond with reduced force in knee joint structures. The current findings show significant reductions in both TF and PF joint contact forces with all three brace models, demonstrating that the TCU brace is capable of providing simultaneous unloading benefits to multiple compartments in the knee. Although our study was planar and therefore unable to quantify force sharing between medial and lateral TF compartments, given the mechanism of unloading (reduced QT and PT forces), it can be reasonably expected that both medial and lateral compartments would experience unloading during the DKB.

This finding differentiates the TCU from traditional unicompartment off-loader braces that are restricted to providing an unloading effect to one side of the TF joint by 


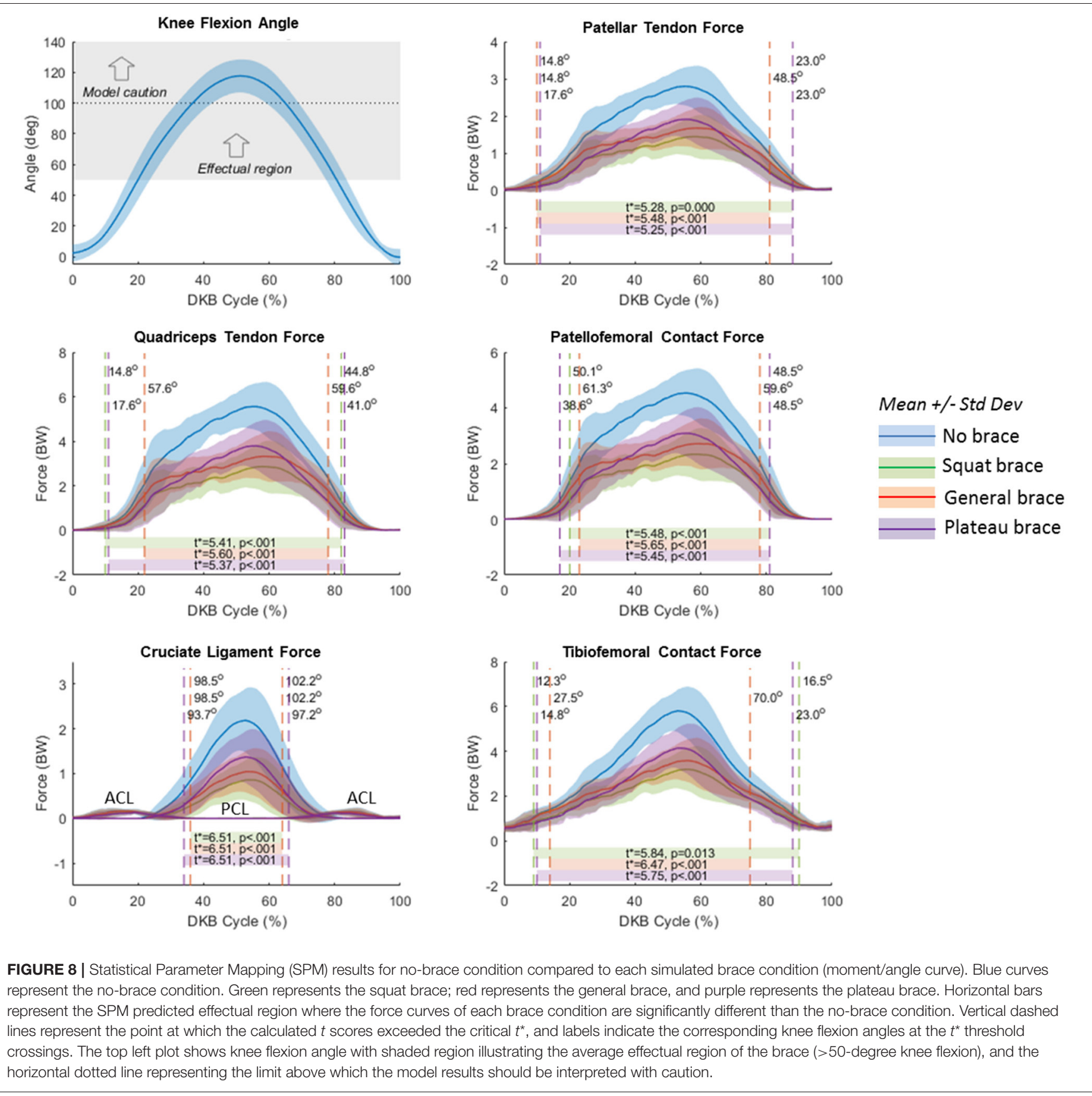

redistributing (or "off-loading") forces to the opposite side of the knee (Gross and Hillstrom, 2008; Ramsey and Russell, 2009; Gohal et al., 2018; Budarick et al., 2020), an effect that could contribute to the development of bicompartmental OA (Gross and Hillstrom, 2008). By unloading all three compartments of the knee joint, the TCU may overcome these limitations while offering patients with $\mathrm{PF}$ or multicompartmental disease a bracing option that better matches their pattern of OA. The reduction in joint force achieved with the TCU is expected to decrease knee pain associated with $\mathrm{OA}$ that results from excessive joint loading (Felson, 2005). Importantly, we found no evidence of significant force increases in any knee tissue structures during the DKB task. This suggests that the TCU brace is safe to use during knee bend activity and should be tested with human participants to determine the effect on knee joint unloading across a range of activities.

The TCU may be of particular interest in the treatment of $\mathrm{PF}$ disorders resulting in $\mathrm{PF}$ pain such as trochlear dysplasia, chondromalacia, patellar tendonitis, and OA. These $\mathrm{PF}$ conditions are considered challenging to treat (McCarthy and Strickland, 2013), and conservative treatment with existing bracing technology that aims to realign the joint has not 
TABLE 2 | Knee forces at 90 degrees of knee flexion [units of body weight (BW)] during observed DKB descent and ascent (non-braced) and with three different simulated TCU brace models for healthy participants $(n=8)$.

\begin{tabular}{|c|c|c|c|c|c|c|c|c|c|c|c|c|c|c|}
\hline \multirow{2}{*}{$\begin{array}{l}\text { Force in } \\
\text { units of BW }\end{array}$} & \multicolumn{2}{|c|}{ No brace } & \multicolumn{2}{|c|}{ Squat brace } & \multicolumn{2}{|c|}{ Effect } & \multicolumn{2}{|c|}{ Gen. brace } & \multicolumn{2}{|c|}{ Effect } & \multicolumn{2}{|c|}{ Plat. brace } & \multicolumn{2}{|c|}{ Effect } \\
\hline & Mean & SD & Mean & SD & $p$ & $d$ & Mean & SD & $p$ & $d$ & Mean & SD & $p$ & $d$ \\
\hline \multicolumn{15}{|l|}{ Descent } \\
\hline$F_{\mathrm{PT}}$ & 2.07 & 0.35 & 1.10 & 0.32 & $<0.001$ & 4.31 & 1.37 & 0.31 & $<0.001$ & 4.32 & 1.26 & 0.32 & $<0.001$ & 4.30 \\
\hline$F_{\mathrm{PF}}$ & 3.46 & 0.59 & 1.84 & 0.54 & $<0.001$ & 4.31 & 2.29 & 0.52 & $<0.001$ & 4.32 & 2.10 & 0.53 & $<0.001$ & 4.30 \\
\hline$F_{\mathrm{QT}}$ & 4.13 & 0.70 & 2.19 & 0.64 & $<0.001$ & 4.31 & 2.73 & 0.63 & $<0.001$ & 4.33 & 2.51 & 0.63 & $<0.001$ & 4.30 \\
\hline$F_{\mathrm{TF}}$ & 2.96 & 0.47 & 1.66 & 0.40 & $<0.001$ & 4.27 & 2.01 & 0.41 & $<0.001$ & 4.37 & 1.86 & 0.41 & $<0.001$ & 4.29 \\
\hline$F_{\mathrm{AC}}$ & 0.00 & 0.00 & 0.02 & 0.02 & 0.049 & -0.84 & 0.01 & 0.01 & 0.351 & -0.35 & 0.01 & 0.02 & 0.281 & -0.41 \\
\hline$F_{\mathrm{PC}}$ & 0.50 & 0.15 & 0.16 & 0.11 & $<0.001$ & 4.66 & 0.23 & 0.13 & $<0.001$ & 4.12 & 0.20 & 0.12 & $<0.001$ & 4.24 \\
\hline \multicolumn{15}{|l|}{ Ascent } \\
\hline$F_{\mathrm{PT}}$ & 2.10 & 0.28 & 1.12 & 0.24 & $<0.001$ & 4.27 & 1.39 & 0.23 & $<0.001$ & 4.27 & 1.28 & 0.23 & $<0.001$ & 4.28 \\
\hline$F_{\mathrm{PF}}$ & 3.50 & 0.47 & 1.88 & 0.39 & $<0.001$ & 4.28 & 2.33 & 0.38 & $<0.001$ & 4.27 & 2.14 & 0.39 & $<0.001$ & 4.29 \\
\hline$F_{\mathrm{QT}}$ & 4.19 & 0.57 & 2.24 & 0.47 & $<0.001$ & 4.27 & 2.78 & 0.46 & $<0.001$ & 4.27 & 2.56 & 0.46 & $<0.001$ & 4.28 \\
\hline$F_{\mathrm{TF}}$ & 2.97 & 0.41 & 1.67 & 0.33 & $<0.001$ & 4.74 & 2.02 & 0.34 & $<0.001$ & 4.47 & 1.87 & 0.34 & $<0.001$ & 4.59 \\
\hline$F_{\mathrm{AC}}$ & 0.00 & 0.00 & 0.01 & 0.03 & 0.148 & -0.57 & 0.00 & 0.00 & - & - & 0.01 & 0.01 & 0.179 & -0.53 \\
\hline$F_{\mathrm{PC}}$ & 0.48 & 0.11 & 0.13 & 0.09 & $<0.001$ & 7.23 & 0.21 & 0.11 & $<0.001$ & 5.09 & 0.19 & 0.10 & $<0.001$ & 7.00 \\
\hline
\end{tabular}

$S D=$ standard deviation, $p=$ significance value (at Bonferroni corrected $\alpha=0.003$ ), $d=$ Cohen $d$ (effect size), $F_{P T}=$ patellar tendon force, $F_{P F}=$ patellofemoral contact force, $F_{Q T}=$ quadriceps tendon force, $F_{T F}=$ Tibiofemoral contact force, $F_{A C}=A C L$ force, $F_{P C}=P C L$ force. Effect for each brace is relative to the no-brace condition.

proven clinically beneficial (Hunter et al., 2011). The TCU brace may also be beneficial during rehabilitation from common knee injuries or surgical procedures. Joint unloading is believed to be beneficial for soft-tissue repair (van der Woude et al., 2017), and progressive weight bearing intended to gradually introduce joint loading is often applied during rehabilitation from meniscal (Cavanaugh and Killian, 2012), cartilage (Mithoefer et al., 2012), ligament (Cavanaugh and Powers, 2017), and tibial plateau fracture repair (Arnold et al., 2017) procedures. Unloading may also have benefits prophylactically, for example, to help prevent the development of knee OA or the occurrence of joint-overuse and joint-stress injuries (Takeda et al., 2011), which may be relevant from an occupational health and safety perspective. Future clinical outcomes research is required to further characterize these and other potential benefits.

\section{Performance of the Knee Model}

The knee model results were largely consistent with results from other knee models evaluated during squat or $\mathrm{DKB}$, in terms of the relative magnitudes of the QT, PT and PF forces (Nisell et al., 1986; Yamaguchi and Zajac, 1989), the transition between AC and PC ligament loading (Beynnon et al., 1996), and the magnitude of TF contact force (Shelburne and Pandy, 2002; Smith et al., 2008). The results of the present investigation also extend the findings of a prior study that calculated the theoretical unloading effect of the TCU at a static $90^{\circ}$ knee bend (Budarick et al., 2020). Briefly, when outlining the design intent for the brace, Budarick et al. (Budarick et al., 2020) calculated that the squat TCU brace model would reduce contact forces of the PF and TF joints by $\sim 22 \%$ at a $90^{\circ}$ knee bend. The results of the present study indicated a larger reduction $(>30-50 \%)$. The difference is explained at least in part by the volunteers that participated in both studies. In the study by Budarick et al. (2020), calculations were based on a single male participant with body mass of $93 \mathrm{~kg}$. In the present study, average body mass of our participants (mostly female) was $66 \mathrm{~kg}$. As the TCU brace applies the same assistive moment regardless of BW, it makes sense that our force reduction estimate is greater than that estimated by Budarick's analysis.

Overall, the knee model performed well under small ( $+/-5 \mathrm{~mm}$ or $+/-5$ degrees) perturbations in the geometric inputs. Figures 5, 6 show that between-subject variability in knee force estimates was greater than the variability in knee forces due to model input errors, up until 90-100 degrees of knee flexion, after which input error influences growth rapidly, similar to that reported by Schellenberg et al. (Schellenberg et al., 2018). On the one hand, these findings suggest that a planar knee model with simple geometric scaling may be sufficient for calculating knee forces during activities having less extreme ranges. On the other hand, our results show that biomechanical analysis of the knee at more extreme flexion angles may require more precise measurement of geometric inputs (e.g., coregistered medical imaging, etc.) and/or a more sophisticated model (e.g., allowing for deformation of ligaments, etc.).

Lower limb bone geometry can be measured with very high accuracy using medical imaging techniques (Van den Broeck et al., 2014). In vivo measurement of cruciate ligament lengths and identification of attachment sites are a greater challenge, but promising results have been published using MRI and computed tomography (Rachmat et al., 2014; Lee et al., 2015), and efforts to automate the segmentation of soft tissues using deep learning approaches may result in more robust solutions (Tack et al., 2018; Mallya et al., 2019). Nevertheless, the capacity to acquire such measures routinely through medical imaging 
is rare. Therefore, our sensitivity analysis should provide some confidence to biomechanical researchers that linear cruciate-TF complex scaling based on anatomical length of the tibia is a good first approximation for the purposes of estimating joint force.

This conclusion was also borne out by the GC analysis, which showed acceptable agreement $(\mathrm{RMSE}=0.7 \mathrm{BW})$ between instrumented and calculated TF force until $\sim 100$ degrees of flexion (or 1.1 BW across the entire range of movement), with mean prediction errors centered near zero (Figure 7). By comparison, in one recent review comparing various state-ofthe-art modeling approaches, RMSE ranged from 0.3 to 0.88 $\mathrm{BW}$ vs. in vivo $\mathrm{TF}$ knee contact measurements during normal gait (Moissenet et al., 2017). Our study was also in general agreement with instrumented knee prosthesis studies (Mizu-uchi et al., 2015; Schellenberg et al., 2018), which consistently show that calculated TF contact force overpredicts the force measured by the prosthesis. It should be recognized that the present knee model has cruciate ligaments, while the GC measured forces are from ligament-sacrificing prostheses that were instrumented and surgically implanted during a TKA procedure. Because cruciate ligaments are capable of transmitting the shear forces across the knee joint to the TF articular surfaces (O'Connor et al., 1990b), our model might be expected to overpredict forces measured from instrumented TKA prostheses.

Finally, the parameter sensitivity analysis performed at 90 degrees of knee flexion (Figure A3) may be useful for identifying the most important variables in the model. For example, the PF and QT forces were most sensitive to the radius of curvature of the PF notch, whereas TF contact forces were most sensitive to the length of the AC ligament and a variety of anatomical measures of the femoral condyle. These findings point to the need for accurate, subject-specific musculoskeletal anatomy to ensure valid force predictions at more extreme knee angles.

\section{Limitations}

While the predicted reductions in knee joint tissue forces with the simulated TCU brace were considerable, they should be considered carefully in light of some of the limitations of the study. For example, we assumed in the simulation that participants were able to adapt muscle effort to produce identical kinematics and kinetics of the lower leg with and without the brace. Support for this assumption is provided by biomechanical studies of experimental exoskeletons that provide an assistive moment to joints of the lower extremity (Kao et al., 2010; Lewis and Ferris, 2011). While these studies did not explore internal joint forces, they do show that humans are quickly able to adapt muscle effort in the presence of an external moment applied to the hip (Lewis and Ferris, 2011) or ankle (Kao et al., 2010) to maintain invariant net joint moments. Therefore, our implicit assumption of invariant net knee moment during the $\mathrm{DKB}$ is reasonable for simulating the action of the TCU.

We also assumed the brace has perfect force transmission to the user (i.e., the spring force in the brace is entirely transmitted as a force perpendicular to the tibia) and that the brace does not deflect or become misaligned with the knee axis of rotation. Future studies applying the brace to human subjects directly will require a means of quantifying force transmission at the skin interface and moment arm of the brace(s) to verify the assistive moment being generated.

In general, the knee model overestimated in vivo $\mathrm{TF}$ forces (Figure 7). The model ignores structures such as collateral ligaments, meniscus, posterior structures (popliteal tendon for example), joint capsule, fascia, and skin. The relative contribution of these structures to sagittal plane joint contact force is likely marginal; nevertheless, ignoring other structures of the knee means that joint forces based on our simple model are probably overestimated. However, the model also ignores co-contraction, so forces may be underpredicted in some circumstances, and these findings may not generalize to OA participants who exhibit elevated co-contraction of leg muscles (Hubley-Kozey et al., 2008).

We interpret our findings as tricompartmental unloading, yet we cannot directly confirm unloading of both medial and lateral condyles of the TF joint with the model we used. The TF contact model is represented in our study by a single set of articulating condyles; therefore, we could only compute the overall joint contact force and not the medial and lateral distribution. It stands to reason, though, that a reduction in knee extensor muscle force would reduce the contact force for both medial and lateral condyles.

A final limitation of this study was the fact that the resulting sample was six females and two males, which prevented any meaningful comparison of biological sex.

\section{CONCLUSIONS}

The biomechanical analysis of the simulated TCU brace provides proof-of-concept evidence in support of a TCU knee extensionassist brace to significantly reduce forces for all major knee structures during a DKB. The primary mechanism of unloading was reduction of muscle forces, which reduced forces transmitted to all internal structures of the knee. Three different TCU brace models were simulated, which altered the degree of brace assistance as expected. This suggests the technology can be developed to provide a customized level of assistance, all which should have a benefit in reducing knee forces, which is the intended benefit of the TCU brace.

\section{DATA AVAILABILITY STATEMENT}

Data supporting the conclusions of this article will be made available by the authors, without undue reservation.

\section{ETHICS STATEMENT}

The studies involving human participants were reviewed and approved by University of New Brunswick, Research Ethics Board. Written informed consent for participation was not required for this secondary study in accordance with the national legislation and the institutional requirements. 


\section{AUTHOR CONTRIBUTIONS}

All authors contributed to the interpretation of the data and drafting the manuscript. CM wrote the computer code for the biomechanical analysis, acquired the data used in the study and conducted the statistical analysis. $\mathrm{EB}$ and $\mathrm{CM}$ developed the knee model sensitivity analysis. SB conducted the Grand Challenge analysis. EB and CC-S generated the brace model data. All authors have read and approved the final submitted version.

\section{FUNDING}

Motion analysis data used for the simulation was funded in part by grants from the Canadian Institutes of Health Research (ROP-

\section{REFERENCES}

Argenson, J.-N. A., Komistek, R. D., Mahfouz, M., Walker, S. A., Aubaniac, J.-M., and Dennis, D. A. (2004). A high flexion total knee arthroplasty design replicates healthy knee motion. Clin. Orthop. 428, 174-179. doi: 10.1097/01.blo.0000148948.79128.76

Arnold, J. B., Tu, C. G., Phan, T. M., Rickman, M., Varghese, V. D., Thewlis, D., et al. (2017). Characteristics of postoperative weight bearing and management protocols for tibial plateau fractures: findings from a scoping review. Injury 48, 2634-2642. doi: 10.1016/j.injury.2017.10.040

Beynnon, B., Yu, J., Huston, D., Fleming, B., Johnson, R., Haugh, L., et al. (1996). A sagittal plane model of the knee and cruciate ligaments with application of a sensitivity analysis. J. Biomech. Eng. 118, 227-239. doi: 10.1115/1.2795965

Block, J. A., and Shakoor, N. (2009). The biomechanics of osteoarthritis: implications for therapy. Curr. Rheumatol. Rep. 11, 15-22. doi: 10.1007/s11926-009-0003-7

Bosmans, L., Valente, G., Wesseling, M., Van Campen, A., De Groote, F., De Schutter, J., et al. (2015). Sensitivity of predicted muscle forces during gait to anatomical variability in musculotendon geometry. J. Biomech. 48, 2116-2123. doi: 10.1016/j.jbiomech.2015.02.052

Brandon, S. C. E., Brown, M. J., Clouthier, A. L., Campbell, A., Richards, J. D., and Deluzio, K. J. (2019). Contributions of muscles and external forces to medial knee load reduction due to osteoarthritis braces. Knee 26, 564-577. doi: 10.1016/j.knee.2019.04.006

Briem, K., and Ramsey, D. K. (2013). The role of bracing. Sports Med Arthrosc Rev. 21, 11-17. doi: 10.1097/JSA.0b013e31827562b5

Budarick, A. R., MacKeil, B. E., Fitzgerald, S., and Cowper-Smith, C. D. (2020). Design and mechanical evaluation of a novel multi-compartment unloader knee brace. J Biomech Eng. 142:014502. doi: 10.1115/1.4044818

Cavanaugh, J. T., and Killian, S. E. (2012). Rehabilitation following meniscal repair. Curr. Rev. Musculoskelet. Med. 5, 46-58. doi: 10.1007/s12178-011-9110-y

Cavanaugh, J. T., and Powers, M. (2017). ACL rehabilitation progression: where are we now? Curr. Rev. Musculoskelet. Med. 10, 289-296. doi: 10.1007/s12178-017-9426-3

Chew, K. T. L., Lew, H. L., Date, E., and Fredericson, M. (2007). Current evidence and clinical applications of therapeutic knee braces. Am. J. Phys. Med. Rehabil. 86, 678-686. doi: 10.1097/PHM.0b013e318114e416

Collins, J. J., and O'Connor, J. J. (1991). Muscle-ligament interactions at the knee during walking. Proc. Inst. Mech. Eng. H. 205, 11-18. doi: 10.1243/PIME_PROC_1991_205_256_02

Dumas, R., Barre, A., Moissenet, F., and Aissaoui, R. (2019). Can a reduction approach predict reliable joint contact and musculo-tendon forces? J. Biomech. 95:109329. doi: 10.1016/j.jbiomech.2019.109329

Duncan, R., Peat, G., Thomas, E., Wood, L., Hay, E., and Croft, P. (2009). Does isolated patellofemoral osteoarthritis matter? Osteoarthr. Cartil. 17, 1151-1155. doi: 10.1016/j.joca.2009.03.016
82960), and Natural Sciences and Engineering Research Council (RGPIN 312529).

\section{ACKNOWLEDGMENTS}

The authors thank students and staff of the UNB Institute of Biomedical Engineering, the Andrew and Marjorie McCain Human Performance Laboratory (UNB Faculty of Kinesiology), and Mr. Bradley Mackeil from Spring Loaded Technology.

\section{SUPPLEMENTARY MATERIAL}

The Supplementary Material for this article can be found online at: https://www.frontiersin.org/articles/10.3389/fbioe. 2020.604860/full\#supplementary-material

Felson, D. T. (2005). The sources of pain in knee osteoarthritis. Curr. Opin. Rheumatol. 17, 624-628. doi: 10.1097/01.bor.0000172800.49120.97

Fregly, B. J., Besier, T. F., Lloyd, D. G., Delp, S. L., Banks, S. A., Pandy, M. G., et al. (2012). Grand Challenge competition to predict in vivo knee loads. J. Orthop. Res. 30, 503-513. doi: 10.1002/jor.22023

Gohal, C., Shanmugaraj, A., Bedi, A., Adili, A., Khan, M., Tate, P., et al. (2018). Effectiveness of valgus offloading knee braces in the treatment of medial compartment knee osteoarthritis: a systematic review. Sports Health. 10, 500-514. doi: 10.1177/1941738118763913

Gross, K. D., and Hillstrom, H. J. (2008). Noninvasive devices targeting the mechanics of osteoarthritis. Rheum. Dis. Clin. North Am. 34, 755-776. doi: 10.1016/j.rdc.2008.06.001

Heekin, R. D., and Fokin, A. A. (2014). Incidence of bicompartmental osteoarthritis in patients undergoing total and unicompartmental knee arthroplasty: is the time ripe for a less radical treatment? J. Knee Surg. 27, 77-81. doi: 10.1055/s-0033-1349401

Hicks, J. L., Uchida, T. K., Seth, A., Rajagopal, A., and Delp, S. L. (2015). Is my model good enough? Best practices for verification and validation of musculoskeletal models and simulations of movement. J. Biomech. Eng. 137:020905. doi: 10.1115/1.4029304

Hubley-Kozey, C., Deluzio, K., and Dunbar, M. (2008). Muscle co-activation patterns during walking in those with severe knee osteoarthritis. Clin. Biomech. Bristol. Avon. 23, 71-80. doi: 10.1016/j.clinbiomech.2007. 08.019

Hunter, D. J., Harvey, W., Gross, K. D., Felson, D., McCree, P., Li, L., et al. (2011). A randomized trial of patellofemoral bracing for treatment of patellofemoral osteoarthritis. Osteoarthr. Cartil. 19, 792-800. doi: 10.1016/j.joca.2010.12.010

Huss, R. A., Holstein, H., and O'Connor, J. J. (2000). A mathematical model of forces in the knee under isometric quadriceps contractions. Clin. Biomech. Bristol. Avon. 15, 112-122. doi: 10.1016/S0268-0033(99) 00059-5

Imran, A., Huss, R. A., Holstein, H., and O'Connor, J. J. (2000). The variation in the orientations and moment arms of the knee extensor and flexor muscle tendons with increasing muscle force: a mathematical analysis. Proc. Inst. Mech. Eng. H. 214, 277-286. doi: 10.1243/0954411001535778

Kao, P. C., Lewis, C. L., and Ferris, D. P. (2010). Invariant ankle moment patterns when walking with and without a robotic ankle exoskeleton. J. Biomech. 43, 203-209. doi: 10.1016/j.jbiomech.2009.09.030

Kapandji, I. A. (1987). “The lower limb," in The Physiology of the Joints, 5th Edn (London: Churchill Livingston), 66-154.

Kazemi, M., Dabiri, Y., and Li, L. P. (2013). Recent advances in computational mechanics of the human knee joint. Comput. Math. Methods Med. 2013:718423. doi: $10.1155 / 2013 / 718423$

Kiebel, S. J., and Friston, K. J. (2004). Statistical parametric mapping for eventrelated potentials (II): a hierarchical temporal model. Neuroimage 22, 503-520. doi: 10.1016/j.neuroimage.2004.02.013 
Komistek, R. D., Dennis, D. A., and Mahfouz, M. (2003). In vivo fluoroscopic analysis of the normal human knee. Clin Orthop. 410, 69-81. doi: 10.1097/01.blo.0000062384.79828.3b

Kuster, M. S. (2002). Exercise recommendations after total joint replacement: a review of the current literature and proposal of scientifically based guidelines. Sports Med. Auckl. N. Z. 32, 433-445. doi: 10.2165/00007256-200232070-00003

Kutzner, I., Trepczynski, A., Heller, M. O., and Bergmann, G. (2013). Knee adduction moment and medial contact force-facts about their correlation during gait. PLoS ONE 8:e81036. doi: 10.1371/journal.pone.0081036

Lee, J. K., Lee, S., Seong, S. C., and Lee, M. C. (2015). Anatomy of the anterior cruciate ligament insertion sites: comparison of plain radiography and three-dimensional computed tomographic imaging to anatomic dissection. Knee Surg. Sports Traumatol. Arthrosc. 23, 2297-2305. doi: 10.1007/s00167-014-3041-2

Lee, P. Y. F., Winfield, T. G., Harris, S. R. S., Storey, E., and Chandratreya, A. (2017). Unloading knee brace is a cost-effective method to bridge and delay surgery in unicompartmental knee arthritis. BMJ Open Sport Exerc. Med. 2, 1-8. doi: 10.1136/bmjsem-2016-000195

Lewis, C. L., and Ferris, D. P. (2011). Invariant hip moment pattern while walking with a robotic hip exoskeleton. J. Biomech. 44, 789-793. doi: 10.1016/j.jbiomech.2011.01.030

Lu, T. W., and O'Connor, J. J. (1996). Fibre recruitment and shape changes of knee ligaments during motion: as revealed by a computer graphics-based model. Proc. Inst. Mech. Eng. H. 210, 71-79. doi: 10.1243/PIME_PROC_1996_210_395_02

Mallya, Y., Venugopal, V., and Mahajan, V. (2019). Automatic delineation of anterior and posterior cruciate ligaments by combining deep learning and deformable atlas based segmentation. Progr. Biomed. Optics Imag. 10953, 1095321-1095321-7. doi: 10.1117/12.2512431

Mastbergen, S. C., Saris, D. B. F., and Lafeber, F. P. J. G. (2013). Functional articular cartilage repair: here, near, or is the best approach not yet clear? Nat. Rev. Rheumatol. 9, 277-290. doi: 10.1038/nrrheum.2013.29

McCarthy, M. M., and Strickland, S. M. (2013). Patellofemoral pain: an update on diagnostic and treatment options. Curr. Rev. Musculoskelet. Med. 6, 188-194. doi: $10.1007 /$ s12178-013-9159-x

McGibbon, C. A., Brandon, S. C. E., Brookshaw, M., and Sexton, A. (2017). Effects of an over-ground exoskeleton on external knee moments during stance phase of gait in healthy adults. Knee 24, 977-993. doi: 10.1016/j.knee.2017. 04.004

Messier, S. P., Resnik, A. E., Beavers, D. P., Mihalko, S. L., Miller, G. D., Nicklas, B. J., et al. (2018). Intentional weight loss in overweight and obese patients with knee osteoarthritis: is more better? Arthritis Care Res. 70, 1569-1575. doi: $10.1002 /$ acr.23608

Mistry, D. A., Chandratreya, A., and Lee, P. Y. F. (2018). An update on unloading knee braces in the treatment of unicompartmental knee osteoarthritis from the last 10 years: a literature review. Surg. J. 4, e110-e118. doi: 10.1055/s-0038-1661382

Mithoefer, K., Hambly, K., Logerstedt, D., Ricci, M., Silvers, H., and Villa, S. D. (2012). Current concepts for rehabilitation and return to sport after knee articular cartilage repair in the athlete. J. Orthop. Sports Phys. Ther. 42, 254-273. doi: 10.2519/jospt.2012.3665

Mizu-uchi, H., Colwell, C. W., Flores-Hernandez, C., Fregly, B. J., Matsuda, S., and D'Lima, D. D. (2015). Patient-specific computer model of dynamic squatting after total knee arthroplasty. J. Arthroplasty. 30, 870-874. doi: 10.1016/j.arth.2014.12.021

Mohamed, A., Baba, J., Beyea, J., Landry, J., Sexton, A., and McGibbon, C. (2012). Comparison of strain-gage and fiber-optic goniometry for measuring knee dynamics during the activities of daily living and exercise. J. Biomech. Eng. 134:084502. doi: 10.1115/1.4007094

Mohamed, A., Sexton, A., Simonsen, K., and McGibbon, C. A. (2019). Development of a mechanistic hypothesis linking compensatory biomechanics and stepping asymmetry during gait of transfemoral amputees. Appl. Bionics Biomech. 2019:4769242. doi: 10.1155/2019/4769242

Moissenet, F., Modenese, L., and Dumas, R. (2017). Alterations of musculoskeletal models for a more accurate estimation of lower limb joint contact forces during normal gait: a systematic review. J. Biomech. 63:8-20. doi: 10.1016/j.jbiomech.2017. 08.025
Morrison, J. B. (1968). Bioengineering analysis of force actions transmitted by the knee joint. Bio Med Eng. 3, 164-170.

Moyer, R. F., Birmingham, T. B., Bryant, D. M., Giffin, J. R., Marriott, K. A., and Leitch, K. M. (2015). Biomechanical effects of valgus knee bracing: a systematic review and meta-analysis. Osteoarthr. Cartil. 23, 178-188. doi: 10.1016/j.joca.2014.11.018

Nisell, R., Nemeth, G., and Ohlsen, H. (1986). Joint forces in extension of the knee. Analysis of a mechanical model. Acta Orthop. Scand. 57, 41-46. doi: 10.3109/17453678608993213

O'Connor, J., Shercliff, T., FitzPatrick, D., Biden, E., and Goodfellow, J. (1990b). "Mechanics of the knee," in Knee Ligaments: Structure, Function, Injury, and Repair, eds D. Daniel, W. Akeson, and J. J. O'Connor (New York, NY: Raven Press, Ltd.), 201-237.

O'Connor, J., Shercliff, T., FitzPatrick, D., Bradley, J., Daniel, D. M., Biden, E., et al. (1990a). "Geometry of the knee," in Knee Ligaments: Structure Function Injury, and Repair, eds D. Daniel, W. Akeson, and J. J. O'Connor (New York, NY: Raven Press Ltd.), 163-199.

O'Connor, J. J., Shercliff, T. L., Biden, E., and Goodfellow, J. W. (1989). The geometry of the knee in the sagittal plane. Proc. Inst. Mech. Eng. H. 203, 223-233. doi: 10.1243/PIME_PROC_1989_203_043_01

Pataky, T. C., Robinson, M. A., and Vanrenterghem, J. (2016). Region-of-interest analyses of one-dimensional biomechanical trajectories: bridging $0 \mathrm{D}$ and $1 \mathrm{D}$ theory, augmenting statistical power. PeerJ. 4:e2652. doi: 10.7717/peerj.2652

Pataky, T. C., Robinson, M. A., Vanrenterghem, J., Savage, R., Bates, K. T., and Crompton, R. H. (2014). Vector field statistics for objective center-of-pressure trajectory analysis during gait, with evidence of scalar sensitivity to small coordinate system rotations. Gait Posture. 40, 255-258. doi: 10.1016/j.gaitpost.2014.01.023

Petersen, W., Ellermann, A., Zantop, T., Rembitzki, I. V., Semsch, H., Liebau, C., et al. (2016). Biomechanical effect of unloader braces for medial osteoarthritis of the knee: a systematic review (CRD 42015026136). Arch Orthop Trauma Surg. 136, 649-656. doi: 10.1007/s00402-015-2388-2

Phillips, S., Li, C. S., Phillips, M., Bischoff, M., Ali, P., Chahal, J., et al. (2016). Treatment of osteoarthritis of the knee with bracing: a scoping review. Orthop. Rev. 8:6256. doi: 10.4081/or.2016.6256

Pollo, F. E., Otis, J. C., Backus, S. I., Warren, R. F., and Wickiewicz, T. L. (2002). Reduction of medial compartment loads with valgus bracing of the osteoarthritic knee. Am. J. Sports Med. 30, 414-421. doi: 10.1177/03635465020300031801

Rachmat, H. H., Janssen, D., Zevenbergen, W. J., Verkerke, G. J., Diercks, R. L., and Verdonschot, N. (2014). Generating finite element models of the knee: how accurately can we determine ligament attachment sites from MRI scans? Med. Eng. Phys. 36, 701-707. doi: 10.1016/j.medengphy.2014.02.016

Radin, E. L., and Burr, D. B. (1984). Hypothesis: Joints can heal. Semin. Arthritis Rheum. 13, 293-302. doi: 10.1016/0049-0172(84)90031-3

Ramsey, D. K., Briem, K., Axe, M. J., and Snyder-Mackler, L. (2007). A mechanical theory for the effectiveness of bracing for medial compartment osteoarthritis of the knee. J. Bone Joint Surg. Am. 89, 2398-2407. doi: 10.2106/00004623-200711000-00009

Ramsey, D. K., and Russell, M. E. (2009). Unloader braces for medial compartment knee osteoarthritis: implications on mediating progression. Sports Health. 1, 416-426. doi: 10.1177/1941738109343157

Rannou, F., Poiraudeau, S., and Beaudreuil, J. (2010). Role of bracing in the management of knee osteoarthritis. Curr. Opin. Rheumatol. 22, 218-222. doi: 10.1097/BOR.0b013e32833619c4

Sarzi-Puttini, P., Cimmino, M. A., Scarpa, R., Caporali, R., Parazzini, F., Zaninelli, A., et al. (2005). Osteoarthritis: an overview of the disease and its treatment strategies. Semin. Arthritis Rheum. 35, 1-10. doi: 10.1016/j.semarthrit.2005.01.013

Sasaki, K., and Neptune, R. R. (2010). Individual muscle contributions to the axial knee joint contact force during normal walking. J. Biomech. 43, 2780-2784. doi: 10.1016/j.jbiomech.2010.06.011

Schellenberg, F., Taylor, W. R., Trepczynski, A., List, R., Kutzner, I., Schütz, P., et al. (2018). Evaluation of the accuracy of musculoskeletal simulation during squats by means of instrumented knee prostheses. Med. Eng. Phys. 61:95-99. doi: 10.1016/j.medengphy.2018.09.004

Shelburne, K. B., and Pandy, M. G. (2002). A dynamic model of the knee and lower limb for simulating rising movements. Comput. 
Methods Biomech. Biomed. Engin. 5, 149-159. doi: 10.1080/10255840290 010265

Shriram, D., Yamako, G., Chosa, E., Lee, Y. H. D., and Subburaj, K. (2019). Effects of a valgus unloader brace in the medial meniscectomized knee joint: a biomechanical study. J. Orthop. Surg. 14, 44. doi: 10.1186/s13018-019-1085-1

Smith, S. M., Cockburn, R. A., Hemmerich, A., Li, R. M., and Wyss, U. P. (2008). Tibiofemoral joint contact forces and knee kinematics during squatting. Gait Posture. 27, 376-386. doi: 10.1016/j.gaitpost.2007. 05.004

Stiehl, J. B., Komistek, R. D., Dennis, D. A., and Keblish, P. A. (2001). Kinematics of the patellofemoral joint in total knee arthroplasty. J. Arthroplasty. 16, 706-714. doi: 10.1054 /arth.2001.24443

Tack, A., Mukhopadhyay, A., and Zachow, S. (2018). Knee menisci segmentation using convolutional neural networks: data from the osteoarthritis initiative. Osteoarthr. Cartil. 26, 680-688. doi: 10.1016/j.joca.2018. 02.907

Takeda, H., Nakagawa, T., Nakamura, K., and Engebretsen, L. (2011). Prevention and management of knee osteoarthritis and knee cartilage injury in sports. Br. J. Sports Med. 45, 304-309. doi: 10.1136/bjsm.2010. 082321

Trepczynski, A., Kutzner, I., Kornaropoulos, E., Taylor, W. R., Duda, G. N., Bergmann, G., et al. (2012). Patellofemoral joint contact forces during activities with high knee flexion. J. Orthop. Res. Off Publ Orthop Res Soc. 30, 408-415. doi: 10.1002/jor.21540

Van den Broeck, J., Vereecke, E., Wirix-Speetjens, R., and Vander Sloten, J. (2014). Segmentation accuracy of long bones. Med. Eng. Phys. 36, 949-953. doi: 10.1016/j.medengphy.2014.03.016

van der Woude, J. A. D., Weigant, K., van Roermund, P. M., Intema, F., Custers, R. J. H., Eckstein, F., et al. (2017). Five-year follow-up of knee joint distraction: clinical benefit and cartilaginous tissue repair in an open uncontrolled prospective study. Cartilage 8, 263-271. doi: 10.1177/19476035166 65442

Waller, C., Hayes, D., Block, J. E., and London, N. J. (2011). Unload it: the key to the treatment of knee osteoarthritis. Knee Surg. Sports Traumatol. Arthrosc. 19, 1823-1829. doi: 10.1007/s00167-011-1403-6

Wijayaratne, S. P., Teichtahl, A. J., Wluka, A. E., Hanna, F., and Cicuttini, F. M. (2007). Patellofemoral osteoarthritis: new insights into a neglected disease. Future Rheumatol. 2, 193-202. doi: 10.2217/17460816.2.2.193
Wilson, D. R., Feikes, J. D., and O'Connor, J. J. (1998). Ligaments and articular contact guide passive knee flexion. J. Biomech. 31, 1127-1136. doi: 10.1016/S0021-9290(98)00119-5

Winby, C. R., Lloyd, D. G., Besier, T. F., and Kirk, T. B. (2009). Muscle and external load contribution to knee joint contact loads during normal gait. J. Biomech. 42, 2294-2300. doi: 10.1016/j.jbiomech.2009.06.019

Wismans, J., Veldpaus, F., Janssen, J., Huson, A., and Struben, P. (1980). A threedimensional mathematical model of the knee-joint. J. Biomech. 13, 677-685. doi: 10.1016/0021-9290(80)90354-1

Yamaguchi, G. T., and Zajac, F. E. (1989). A planar model of the knee joint to characterize the knee extensor mechanism. J. Biomech. 22, 1-10. doi: 10.1016/0021-9290(89)90179-6

Zavatsky, A. B., and O'Connor, J. J. (1992a). A model of human knee ligaments in the sagittal plane. Part 1: response to passive flexion. Proc. Inst. Mech. Eng. H. 206, 125-134. doi: 10.1243/PIME_PROC_1992_206_280_02

Zavatsky, A. B., and O'Connor, J. J. (1992b). A model of human knee ligaments in the sagittal plane. Part 2: fibre recruitment under load. Proc. Inst. Mech. Eng. H. 206, 135-145. doi: 10.1243/PIME_PROC_1992_206_281_02

Zhang, W., Moskowitz, R. W., Nuki, G., Abramson, S., Altman, R. D., Arden, N., et al. (2008). OARSI recommendations for the management of hip and knee osteoarthritis, Part II: OARSI evidence-based, expert consensus guidelines. Osteoarthr. Cartil. 16, 137-162. doi: 10.1016/j.joca.2007. 12.013

Conflict of Interest: CC-S was President and CEO of Spring Loaded Technologies Inc.

The remaining authors declare that the research was conducted in the absence of any commercial or financial relationships that could be construed as a potential conflict of interest.

Copyright (๐ 2021 McGibbon, Brandon, Bishop, Cowper-Smith and Biden. This is an open-access article distributed under the terms of the Creative Commons Attribution License (CC BY). The use, distribution or reproduction in other forums is permitted, provided the original author(s) and the copyright owner(s) are credited and that the original publication in this journal is cited, in accordance with accepted academic practice. No use, distribution or reproduction is permitted which does not comply with these terms. 